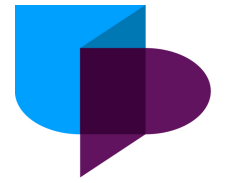

UNIVERSITYOF

PORTSMOUTH

Working Papers in Economics \& Finance

2020-12

\title{
Lying for Others: The Impact of Agency on Misreporting
}

Georgia E. Buckle, University of Portsmouth Sascha Füllbrunn, Radboud University Wolfgang J. Luhan, University of Portsmouth 


\title{
Lying for Others: The Impact of Agency on Misreporting*
}

\author{
Georgia E. Buckle ${ }^{\mathrm{a}}$, Sascha Füllbrunn ${ }^{\mathrm{b}}$, Wolfgang J. Luhan ${ }^{\mathrm{c}}$ \\ ${ }^{a}$ University of Portsmouth, Economics and Finance Subject Group, Faculty of Business and Law, Richmond \\ Building, Portland Street, Portsmouth PO1 3DE, United Kingdom \\ ${ }^{b}$ Radboud University, Institute for Management Research, Department of Economics and Business \\ Economics, Heyendaalseweg 141, 6525 AJ Nijmegen, The Netherlands \\ ${ }^{c}$ Corresponding Author: University of Portsmouth, Economics and Finance Subject Group, Faculty of \\ Business and Law, Richmond Building, Portland Street, Portsmouth PO1 3DE, United Kingdom
}

\begin{abstract}
We extend the experimental design by Fischbacher and Föllmi-Heusi (2013) to examine lying behavior on behalf of others, eliminating all possible incentives apart from social preferences. We compare the prevalence of misreporting in situations where the monetary gain either goes to the decision-maker or to an anonymous other participant. Overall we observe lower levels of lying for others compared to for oneself, however, a significant number of participants were willing to lie to increase another participant's payoff, with no economic incentive to do so. We find no partial lying for others but rather two extremes: either complete honesty or maximal lying.
\end{abstract}

JEL: C91, D63, D82

Keywords: lying aversion, decision making for others, prosocial lying, experiment

\footnotetext{
${ }^{\star}$ We thank participants at the 2017 ESA European Meeting in Vienna, the 2018 ESA World Meeting in Berlin, and seminar participants in Portsmouth for helpful comments. We gratefully aknowlege finacial support from a BA/Leverhulme Small Research Grant (SG162815).

Email addresses: Georgia.Buckle@port.ac.uk (Georgia E. Buckle), s.fullbrunn@fm.ru.nl (Sascha Füllbrunn), wolfgang.luhan@port.ac.uk (Wolfgang J. Luhan)
} 


\section{Introduction}

Private information - and the potential material gain from misreporting such information is a core element of various economic situations (e.g., filing tax returns, making insurance claims, writing $\mathrm{CVs}$ ). In previous experimental research, subjects have been put in scenarios where they can misreport private information for their own monetary benefit, and consistently subjects displayed an aversion for lying and a preference for appearing honest (see, e.g., Abeler et al., 2019, Jacobsen et al., 2018, for an overview). In everyday life, however, decision-makers often do not act on behalf of themselves but on behalf of others (see, e.g., Füllbrunn et al., 2020) and are willing misreport the other's private information to the financial advantage of this person. For example, parents will misreport for their children (Houser et al., 2016), external auditors have been found to misrepresent the financial conditions of their clients (Gawn and Innes, 2019), and in publicly held corporations, declarations of legal reductions in taxable income are mostly made by tax advisers (Crocker and Slemrod, 2005). In contrast to previous studies that examined the monetary incentives for lying for self-benefit (e.g., Crocker and Slemrod, 2005), we focus on the underlying, non-monetary motivations for dishonest behavior on behalf of others. Our study is the first that experimentally considers 'lying for others' in 'social tasks' (see section 3.3 in Jacobsen et al., 2018) and the first controlled laboratory experiment that considers 'pure' lying for others without external influences on behavior.

On the one hand, without any tangible incentives for the decision-maker, the intrinsic costs of lying (Fischbacher and Föllmi-Heusi, 2013, Gneezy, 2005) should decrease or even eliminate lying for others. On the other hand, an extensive literature on decision making for others shows that feelings of responsibility result in pro-social actions (e.g., Bolton et al., 2015; Charness, 2000, Charness and Jackson, 2009; Füllbrunn and Luhan, 2020) which suggests that, under responsibility, people might lie for others to increase their payoff. Given these two conflicting predictions, we ask the question: "Are agents more or less willing to lie for others than for themselves?"

To make our results comparable to the existing literature on lying aversion, we extend the prominent design by Fischbacher and Föllmi-Heusi (2013) in which a die is rolled in private and the reported outcome determines the participant's payoff. In our setting participants rolled the die to determine their own payoff, or the payoff of an anonymous other participant with no incentive for themselves. Without the possibility of detection and a monetary incentive to lie in this setting, economic theory would predict maximal overreporting of the die roll for oneself, but a long list of experiments have found that people shy away from lying and that they display various levels of lying costs (Gneezy et al., 2013, Jacobsen et al., 2018, Mazar et al., 2008). When reporting for others, however, previous studies have demonstrated that even in the absence of monetary incentives, lying costs can be counteracted by group loyalty (Cadsby et al. 2016), social bonds (Aksoy and Palma, 
2019), and fairness concerns (Okeke and Godlonton, 2014). Our aim is to examine the core effect of social preferences without these external incentives, in an anonymous, controlled laboratory experiment to establish a baseline trade-off between lying aversion and the feeling of responsibility.

\section{Experimental Design}

We closely follow the original design of Fischbacher and Föllmi-Heusi (2013) with the new treatment as the only adjustment 1 The participants received a die and on-screen instructions. We asked them to roll the die in private and report the result to determine their payment. Reporting 1 , $2,3,4$ or 5 would result in an equivalent payment in euro (one representing $€ 1$ etc.) and reporting 6 in payment of zero euro. As in Fischbacher and Föllmi-Heusi (2013), we attached this experiment to the end of a previous experiment which allowed us to pay participants a cumulative payoff from both experiments, increasing the anonymity of the decision 2

In our baseline treatment, OWN, each subject reported the outcome of the die roll to determine her or his own payment as in Fischbacher and Föllmi-Heusi (2013). In our treatment OTH subjects were split into two groups, active decision-makers and passive receivers. The active decisionmakers rolled the die and reported the outcome, which determined a random anonymous passive participant's payment, while the decision-maker earned nothing. In order to reduce perceived anticipation effects of the decision-maker, the receivers did not know anything about the task of the decision-makers, and the decision-makers were informed about this Atanasov and Dana, 2011). The receivers were informed of the outcome only, and were asked to fill in a questionnaire while they were waiting. We implemented a one-shot between-subjects design to avoid the first decision providing a psychological anchor for any subsequent decisions. Due to the simple and short instructions, the task took less than five minutes.

In the previous literature, researchers have considered several theories to explain lying behavior (Jacobsen et al. 2018). We concentrate on the relevant ones for our setting. In OWN, the economic model of crime and dishonesty by Becker (1968) predicts the decision-maker to always report the highest payoff (five). The utility of the monetary reward outweighs the risk of detection and the costs of punishment, which are virtually zero in this experimental setting. As mentioned above, intrinsic lying aversion deters people to some extent from overreporting, due to a moral cost from the act of lying itself and a reputational cost associated with being seen as a liar (Gneezy et al. 2018. Mazar et al. 2008). Other theories that predict changes in dishonest behavior include 'Self-Concept Maintenance Theory' (acting immorally within a limited framework), 'Self-Serving Justifications'

\footnotetext{
${ }^{1}$ The instructions can be found in the online-appendix.

${ }^{2}$ Neither the type of the preceding experiment, nor the the decision-maker's payoff from that experiment had a significant effect on the reported number in either treatment.
} 
(shift moral standards to justify overreporting), 'Moral Disengagement' (subjects excuse themselves from moral rule they apply to others) or 'Bounded Ethicality' (unawareness of ethical norms) ${ }^{3}$

For OTH, standard economic theory predicts no lying. Without incentives, truthful reporting involves the lowest (cognitive) 'effort' for the decision-maker. The same applies to lying aversion as there is no monetary incentive to outweigh the lying costs, so nothing to motivate any deviation from the true result. However, an in crease in pro-social behavior due to perceived responsibility for others (Charness, 2000; Charness and Jackson, 2009) might cause an increase in over-reporting (as compared to OWN) as decision-makers want to increase the receiver's payoff by telling 'altruistic white lies' (Erat and Gneezy, 2012). We might also observe antisocial lying in OTH. As the payment for the decision-maker is zero, dishonestly reporting a six, to also lower the receiver's payment to zero, might satisfy fairness preferences and in particular, inequality aversion. (Fehr and Schmidt, 1999: Bolton and Ockenfels, 2000). Therefore the (extreme) prediction on OTH include a bi-modal distribution with peaks in five and zero.

We programmed and conducted the experiment using Z-Tree (Fischbacher, 2007) and used ORSEE for the recruitment (Greiner, 2015). In total, 282 subjects (117 male, 165 female) from various fields participated in 18 separated sessions in the IMR laboratory at Radboud University in Nijmegen (NL). After reporting, subjects filled in a short questionnaire and were paid privately and in cash.

\section{Results}

Figure 1 depicts the two distributions of claimed payoffs for the two treatments. Both distributions are different from the expected distribution of a fair die roll - represented by the dashed line - which is confirmed by a Kolmogorov- Smirnov test (OWN p $<.001$; OTH p $<.001$ ). The distribution for OWN resembles the reported results from the literature on lying aversion (see, e.g. Fischbacher and Föllmi-Heusi, 2013, Figure 1). The subjects reported a payoff of four and five more often than expected (binomial tests, $\mathrm{p}<0.001$ ), indicating that there was both maximal and partial lying, they reported zero, one, two and three less often than expected (binomial tests, $\mathrm{p}<$ $0.01)$.

The distribution of reported payoffs in OTH is significantly different from OWN (KolmogorovSmirnov $\mathrm{p}=.099$, Fisher-Pitman permutation $\mathrm{p}=.008)$ with the average claim in OTH $(2.83)$ being significantly lower than in OWN (3.35) according to a one-tailed permutation test ( $\mathrm{p}=0.004)$. The subjects over-report five (binomial test, $\mathrm{p}=0.015$ ) but we find no significant differences from the theoretical distribution in any other outcome (binomial test, $\mathrm{p}>0.1$ ) suggesting that

\footnotetext{
${ }^{3}$ Find references and discussions in Jacobsen et al. (2018).
} 


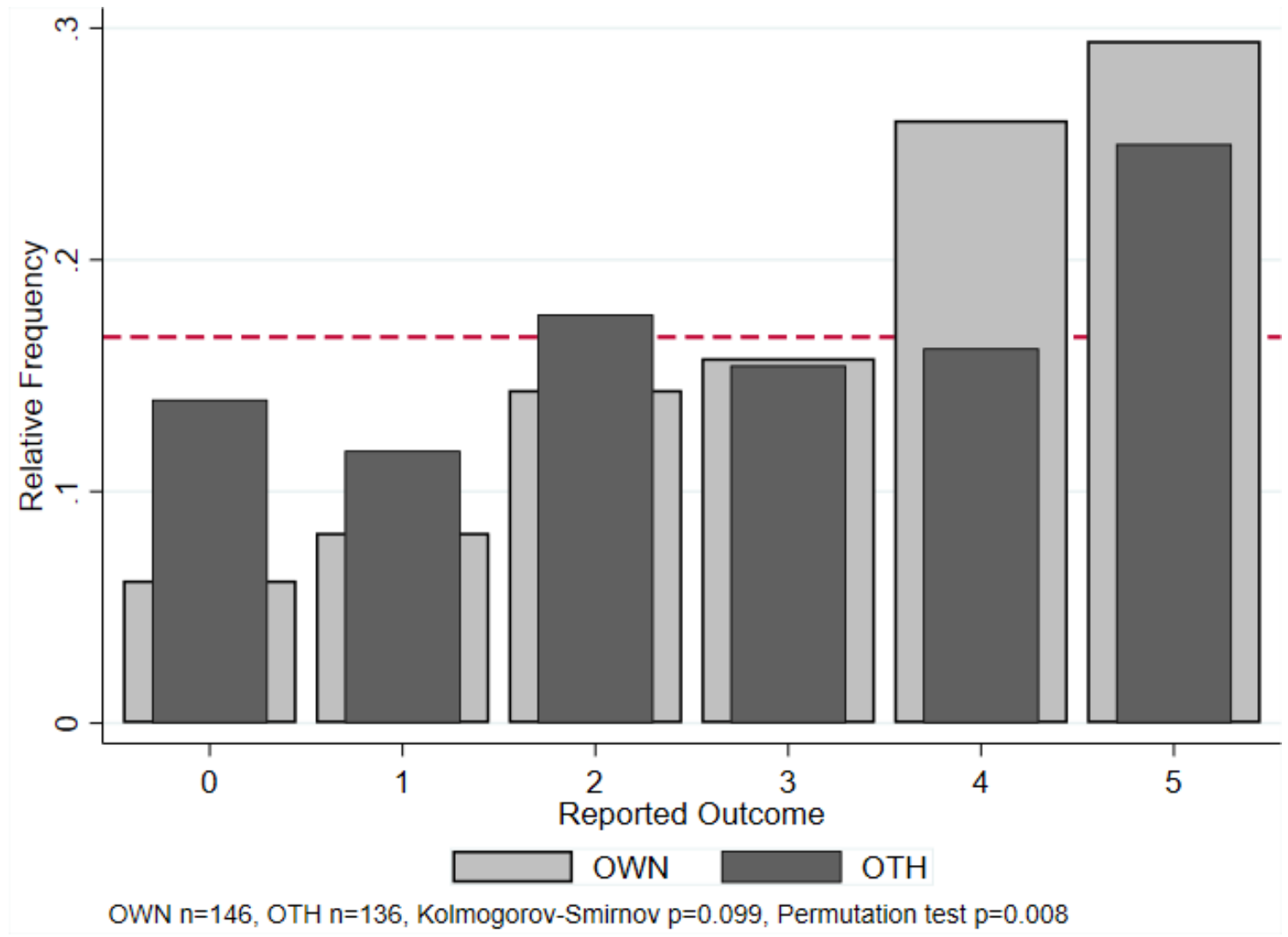

Figure 1: Distribution of claimed payoffs. The dashed line indicates the expected distribution from a fair die roll. 
those participants who did lie prosocially, did so to the maximal extent. There is a significant difference between the reported claims of 4 across treatments $(p=0.008)$ again indicating that fewer participants lied partially for others. Apparently, subjects are either willing fully lie for others or do not lie at all.

Our results show that a number of subjects are willing to lie for their recipients and claim the highest outcome, despite having no monetary or strategic incentive to do so. For this group of participants their social preferences appear to outweigh their intrinsic lying costs. The majority of participants, however, reports the true result of the die roll for others with overall less lying in OTH than in OWN.

Finally we see no significant over-reporting of zero in OTH, we can conclude that inequalityaversion seems to play no particular role.

\section{Discussion and Conclusion}

We have asked the question whether people are more or less willing to lie for others than for themselves in the absence of monetary incentives for the decision-maker. We extended the popular design by Fischbacher and Föllmi-Heusi (2013) to study lying aversion for others. In our design we eliminate any motivation for lying on behalf of others apart from basic social preferences, such as responsibility or fairness. Overall, we find that our subjects lie significantly less for others than for themselves. A small number of subjects are willing to lie maximally for others by reporting the highest payoff, but the majority of subjects appears to truthfully report the outcome of the die roll. In contrast to this, we find the same pattern and level of lying and lying aversion as in the literature when making decisions for oneself.

This result does not necessarily contradict the finding that feelings of responsibility evoke greater social preferences, which has been found in previous studies on decision making for others (e.g., Bolton et al., 2015, Charness, 2000, Charness and Jackson, 2009, Füllbrunn and Luhan, 2020). This simply indicates that these social preferences do not weigh as strongly as monetary incentives when pitted against lying aversion. We observed an absence of partial lying which could be an indication of lower lying costs due to a different perception of social norms in lies for others. If lying is perceived as socially acceptable when the aim is to help others (see, e.g., Levine and Schweitzer, 2014: Lindskold and Han, 1986) the social image costs that cause people to disguise their behavior with partial lies (see Abeler et al. 2019, Gneezy et al. 2018, for a discussion) may be alleviated. Such behavior would lead to reports of only 5 - at least for the group of people who hold this view. This effect would have to be the subject of a further experiment, however. 


\section{References}

Abeler, J., Nosenzo, D., Raymond, C., 2019. Preferences for truth-telling. Econometrica 87, 11151153.

Aksoy, B., Palma, M.A., 2019. The effects of scarcity on cheating and in-group favoritism. Journal of Economic Behavior \& Organization 165, 100-117.

Atanasov, P., Dana, J., 2011. Leveling the playing field: Dishonesty in the face of threat. Journal of Economic Psychology 32, 809-817.

Becker, G.S., 1968. Crime and punishment: An economic approach, in: The economic dimensions of crime. Springer, pp. 13-68.

Bolton, G.E., Ockenfels, A., 2000. Erc: A theory of equity, reciprocity, and competition. American Economic Review 90, 166-193.

Bolton, G.E., Ockenfels, A., Stauf, J., 2015. Social responsibility promotes conservative risk behavior. European Economic Review 74, 109 - 127.

Cadsby, C.B., Du, N., Song, F., 2016. In-group favoritism and moral decision-making. Journal of Economic Behavior \& Organization 128, 59-71.

Charness, G., 2000. Responsibility and effort in an experimental labor market. Journal of Economic Behavior \& Organization 42, 375-384.

Charness, G., Jackson, M.O., 2009. The role of responsibility in strategic risk-taking. Journal of Economic Behavior \& Organization 69, 241-247.

Crocker, K.J., Slemrod, J., 2005. Corporate tax evasion with agency costs. Journal of Public Economics 89, 1593-1610.

Erat, S., Gneezy, U., 2012. White lies. Management Science 58, 723-733.

Fehr, E., Schmidt, K.M., 1999. A theory of fairness, competition, and cooperation. The Quarterly Journal of Economics 114, 817-868.

Fischbacher, U., 2007. z-tree: Zurich toolbox for ready-made economic experiments. Experimental Economics 10, 171-178.

Fischbacher, U., Föllmi-Heusi, F., 2013. Lies in disguise - an experimental study on cheating. Journal of the European Economic Association 11, 525-547. 
Füllbrunn, S., Luhan, W., Sanfey, A., 2020. Current issues in decision making for others. Journal of Economic Psychology , 102250.

Füllbrunn, S., Luhan, W.J., 2020. Responsibility and limited liability in decision making for othersan experimental consideration. Journal of Economic Psychology 77, 102186.

Gawn, G., Innes, R., 2019. Lying through others: Does delegation promote deception? Journal of Economic Psychology 71, 59-73.

Gneezy, U., 2005. Deception: The role of consequences. American Economic Review 95, 384-394.

Gneezy, U., Kajackaite, A., Sobel, J., 2018. Lying aversion and the size of the lie. American Economic Review 108, 419-53.

Gneezy, U., Rockenbach, B., Serra-Garcia, M., 2013. Measuring lying aversion. Journal of Economic Behavior \& Organization 93, 293-300.

Greiner, B., 2015. Subject pool recruitment procedures: organizing experiments with orsee. Journal of the Economic Science Association 1, 114-125.

Houser, D., List, J.A., Piovesan, M., Samek, A., Winter, J., 2016. Dishonesty: From parents to children. European Economic Review 82, 242-254.

Jacobsen, C., Fosgaard, T.R., Pascual-Ezama, D., 2018. Why do we lie? a practical guide to the dishonesty literature. Journal of Economic Surveys 32, 357-387.

Levine, E.E., Schweitzer, M.E., 2014. Are liars ethical? on the tension between benevolence and honesty. Journal of Experimental Social Psychology 53, 107-117.

Lindskold, S., Han, G., 1986. Intent and the judgment of lies. The Journal of social psychology .

Mazar, N., Amir, O., Ariely, D., 2008. The dishonesty of honest people: A theory of self-concept maintenance. Journal of marketing research 45, 633-644.

Okeke, E.N., Godlonton, S., 2014. Doing wrong to do right? social preferences and dishonest behavior. Journal of Economic Behavior \& Organization 106, 124-139. 